\title{
Estimativas de herdabilidades e correlações genéticas entre características reprodutivas em touros da raça Nelore
}

[Genetic correlations and heritability estimates of reproductive traits of Nellore bulls]

\author{
T.S. Silveira ${ }^{1}$, J.B. Siqueira ${ }^{2 *}$, L.R. Sarmente ${ }^{3}$, J.P. Eler ${ }^{3}$, R.A. Torres ${ }^{4}$, S.E.F. Guimarães ${ }^{4}$, \\ T. Miranda Neto ${ }^{5}$, J.D. Guimarães ${ }^{4}$ \\ ${ }^{1}$ Médico Veterinário autônomo \\ ${ }^{2}$ Universidade Federal do Espírito Santo - Alegre, ES \\ ${ }^{3}$ Faculdade de Zootecnia e Engenharia de Alimentos - Universidade de São Paulo - São Paulo, SP \\ ${ }^{4}$ Universidade Federal de Viçosa - Viçosa, MG \\ ${ }^{5}$ Agropecuária CFM Ltda - São José do Rio Preto, SP
}

\begin{abstract}
RESUMO
Foram obtidas estimativas de variância fenotípica, genética e residual, herdabilidades e correlações genéticas para as características reprodutivas em 5.903 animais da raça Nelore. O modelo experimental utilizado foi o método de máxima verossimilhança restrita livre de derivadas. Os valores de herdabilidade foram de $0,24 \pm 0,05$ para perímetro escrotal aos 450 dias de idade e de $0,37 \pm 0,05$ aos 21 meses de idade, na ocasião do exame andrológico; de $0,24 \pm 0,05$ e $0,26 \pm 0,05$ para comprimento dos testículos esquerdo e direito; de $0,29 \pm 0,05$ e $0,31 \pm 0,05$ para largura dos testículos esquerdo e direito; de $0,12 \pm 0,04$ para formato testicular; de 0,33 $\pm 0,06$ para volume testicular; de $0,11 \pm 0,03$ para turbilhonamento; de $0,08 \pm 0,03$ para motilidade e de $0,05 \pm 0,02$ para vigor espermático; de $0,20 \pm 0,04,0,03 \pm 0,02$ e $0,19 \pm 0,04$ para defeitos espermáticos maiores, menores e totais, respectivamente. As características biométricas testiculares apresentaram valores de herdabilidade moderados a altos, enquanto as características seminais valores baixos. Correlações genéticas entre perímetro escrotal com todas as características reprodutivas foram favoráveis, o que sugere o perímetro escrotal como característica de escolha na seleção de touros.
\end{abstract}

Palavras-chave: Nelore, exame andrológico, herdabilidade

\begin{abstract}
Estimates of phenotypic, genetics and residual variances for reproductive traits in 5903 Nellore bulls were obtained. The experimental model used was multiple trait derivative-free restricted maximum likelihood. The values obtained for heritability were $0.24 \pm 0.05$ for scrotal circumference at 450 days of age and $0.37 \pm 0.05$ at 21 months for age at the time of the breeding soundness evaluation; $0.24 \pm 0.05$ and $0.26 \pm 0.05$ for left and right testicle length; $0.29 \pm 0.05$ and $0.31 \pm 0.05$ for left and right testicle width; $0.12 \pm 0.04$ for testicle format; $0.33 \pm 0.06$ for testicle volume; $0.11 \pm 0.03$ for gross motility; $0.08 \pm 0.03$ for individual motility and $0.05 \pm 0.02$ for spermatic vigor; $0.20 \pm 0.04,0.03 \pm 0.02$ and $0.19 \pm 0.04$ for larger defects, smaller defects and total defects, respectively. The values for heritability for testicular biometric characteristics were moderate to high while the seminal characteristics, presented low values. Genetic correlations between scrotal circumference with all the reproductive traits were favorable, suggesting the scrotal circumference as a feature of choice in the selection of bulls.
\end{abstract}

Keywords: Nelore, breeding soundness evaluation, heritability

\section{INTRODUÇÃO}

A necessidade de conhecer as relações genéticas das características reprodutivas em animais zebuínos, principalmente na raça Nelore, surge em primeira instância, para o direcionamento dos programas de melhoramento genético da raça. Atualmente, há necessidade de adaptação da raça

Recebido em 5 de setembro de 2012

Aceito em 10 de dezembro de 2012

*Autor para correspondência (corresponding author)

E-mail: jbsiqueira_@hotmail.com 
aos novos padrões de produtividade exigidos pelos agentes produtivos, que necessitam de animais terminados com mais rapidez e melhor qualidade de carcaça. Contudo, para alcançar essa meta, conhecimentos mais detalhados sobre os aspectos de precocidade, tanto de crescimento como de desenvolvimento sexual, são necessários.

Conhecer a genética das características reprodutivas dos machos ganha importância quando se pretende maximizar a produtividade (Souza et al., 1997). O impacto econômico do melhoramento genético do macho na produção e na reprodução é maior que o da fêmea bovina, visto que o número de descendentes deixados por um touro por ciclo produtivo em rebanhos de produção é muitas vezes maior que o alcançado por uma fêmea (Corah et al., 1994).

As características utilizadas como critério de seleção para alcançar melhora genética em bovinos de corte no Brasil são, principalmente, as de crescimento. Segundo Vasconcelos Silva et al. (2001), a seleção de características reprodutivas diretamente ligadas à precocidade $\mathrm{e}$ à fertilidade sexual não é simples, apresentando dificuldades desde o momento da coleta de dados até a análise estatística e a predição dos valores genéticos. Além disso, as características reprodutivas, em geral, apresentam baixa herdabilidade.

Nos machos, o perímetro escrotal (PE) é a principal característica reprodutiva incluída nos programas de melhoramento genético de bovinos de corte. Segundo Toelle e Robison (1985) e Pereira et al. (2000), a estimativa de herdabilidade do PE é maior que a de características reprodutivas de fêmeas, por isso ele é utilizado em programas de melhoramento genético, visando otimizar a eficiência reprodutiva e também reduzir a idade à puberdade de machos e fêmeas. Adicionalmente, é uma mensuração facilmente obtida e com alta repetibilidade entre avaliadores, apresentando alta correlação com o ganho de peso e as características reprodutivas das fêmeas e dos machos.

Neste estudo, objetivou-se estimar as variâncias genéticas, fenotípicas e residuais, assim como herdabilidades e correlações genéticas de características reprodutivas em touros da raça Nelore criados extensivamente.

\section{MATERIAL E MÉTODOS}

Foram utilizados 5.903 touros jovens da raça Nelore com registro genealógico, nascidos nas estações de parição, de agosto a dezembro, nos anos de 1997 a 2001, no município de Magda, situada na região noroeste do estado de São Paulo. Os animais foram criados em regime extensivo até 18 meses de idade, com pastagem predominantemente de capim braquiária (Brachiaria decumbens) e colonião (Panicum maximum). Posteriormente, foram confinados e alimentados com silagem de milho, sal mineral e água ad libitum. Na faixa etária de 20 a 22 meses de idade, foram realizados os exames andrológicos.

Durante o exame andrológico, foi realizada a mensuração de comprimento e de largura testicular em centímetros, obtida com auxílio de paquímetro, e a do perímetro escrotal, com ajuda de fita métrica, na região mais larga do escroto após leve tracionamento ventrocaudal das gônadas. Para determinação do formato testicular, foram adotados os critérios utilizados por Bailey et al. (1996) e Bailey et al. (1998), a partir da razão entre largura e comprimento testicular médio, sendo classificados em cinco classes: longo (razão $\leq 0,5$ ), longo-moderado (razão de 0,51 a 0,625), longo-oval (razão de 0,626 a 0,750), oval-esférico (razão de 0,751 a 0,875 ) e esférico (razão $\geq 0,875$ ). Empregou-se a classe do formato testicular para determinar $\mathrm{o}$ volume testicular, adotando-se as formas preconizadas por Fields et al. (1979) para testículos em formato cilíndrico - longo, longomoderado e longo-oval - e de Bailey et al. (1998) para testículos com formato esférico ovoide-esférico e esférico. O perímetro escrotal ajustado para 450 dias de idade (PE450) e na ocasião do exame andrológico (PE) foi englobado nas características biométricas reprodutivas.

A avaliação das características físicas do ejaculado foi realizada logo após a coleta do sêmen pelo método de eletroejaculação. Foi analisado o movimento em massa dos espermatozoides - turbilhonamento -, em uma escala de 1 a 5, motilidade espermática 
progressiva retilínea - $0-100 \%$ - e vigor espermático - escala de 0 a 5 -, com aumento de 200X em microscópio de contraste de fase da marca OLYMPUS modelo 400B. Para análise morfológica dos espermatozoides, uma amostra de sêmen foi acondicionada e estocada em $1 \mathrm{~mL}$ de solução salina tamponada de formol (Hancock, 1957). Nesta avaliação, adotou-se a metodologia preconizada por Blom (1983), classificando as anomalias em defeitos espermáticos maiores, menores e totais.

Com o intuito de apresentar estimativas de (co)variâncias e de parâmetros genéticos para as características descritas acima, foram realizadas análises unicaracterísticas sob modelo misto, pelo método da máxima verossimilhança restrita livre de derivadas, por meio do software multiple trait derivative-free restricted maximum likelihood (MTDFREML) descrito por Boldman e Van Vleck (1993).

A definição do modelo a ser utilizado foi auxiliada pela avaliação da significância da inclusão de variáveis no modelo e na análise pelo pacote estatístico SAS (1999). Para as análises do perímetro escrotal aos 450 dias de idade, o modelo estatístico foi composto pelos efeitos fixos de pai, ano do exame andrológico, classe andrológica, interação ano de exame andrológico e classe andrológica e idade da mãe ao parto, como covariáveis linear e quadrática. Para as demais características relacionadas à reprodução, a co-variável idade da mãe foi substituída por idade do animal na ocasião do exame andrológico.

Para o conjunto de dados em questão, foram considerados 167 grupos de contemporâneos, que levavam em consideração safra de nascimento, grupo de manejo à desmama e grupo de manejo ao sobreano. Para o PE450, também foram incluídos no modelo os efeitos linear e quadrático da idade da mãe ao parto como covariáveis e o efeito de ambiente permanente materno.

Os valores iniciais dos componentes de variâncias genética e residual foram obtidos a partir do desvio-padrão da característica. Nas análises conjuntas com duas características, os componentes de variância utilizados foram os estimados nas análises com uma característica.
Nas análises que consideraram o efeito materno, a covariância entre efeitos genéticos direto e materno foi considerada igual a zero (Marcondes et al., 2002). Os valores iniciais de covariâncias genética e residual foram obtidos pela fórmula de determinação das correlações descrita por Henderson e Quaas (1976).

\section{RESULTADOS E DISCUSSÃO}

Os valores obtidos para as estimativas de componentes de variância fenotípica $\left(\sigma_{p}^{2}\right)$, genética aditiva direta $\left(\sigma_{a}^{2}\right)$, genética aditiva materna $\left(\sigma_{m}^{2}\right)$ e residual $\left(\sigma_{e}^{2}\right)$ estão sumariados na Tab. 1.

$\mathrm{O}$ valor das herdabilidades aditiva direta $\mathrm{e}$ materna para PE450 foi de 0,24 e 0,10, respectivamente, demonstrando que até a idade de 450 dias ainda há influência considerável da genética materna no desenvolvimento reprodutivo do futuro touro. Portanto, espera-se que touros filhos de mães com maior habilidade materna tenham desenvolvimento reprodutivo mais precocemente.

Os valores observados para PE na literatura apresentam herdabilidades médias a altas, assim como registrado neste estudo $(0,37)$, para herdabilidade aditiva direta. Em estudos realizados com animais da raça Nelore, no Brasil e no Paraguai, foram observados valores muito próximos: de 0,30 por Sarreiro et al. (2000), de 0,40 e 0,41 (corrigido para idade) por Sarreiro (2001) e Ortiz Peña et al. (2001), respectivamente, de 0,38 por Sarreiro et al. (2002), de 0,43 por Dias et al. (2000) e de 0,36 por Garnero et al. (2001). Ainda, com animais da mesma raça, outros autores registraram valores mais altos, como Eler et al. (1996), 0,52, Pereira et al. (2000), 0,51, e Ortiz Peña et al. (2001), 0,47 (valor corrigido para idade e peso corporal). Entretanto, valores mais altos de herdabilidade para $\mathrm{PE}$, em touros da raça Nelore, foram registrados por Quirino (1999), 0,81 - não ajustado para peso corporal -, e 0,71 - ajustado para peso corporal -; por Bergmann et al. (1997), 0,87, e Dias (2004), 1,00. Todos os valores apresentados, inclusive os deste estudo, demonstram a existência de variância genética aditiva favorável para seleção de reprodutores baseada no PE. 
Tabela 1. Estimativas de variância fenotípica $\left(\sigma_{p}^{2}\right)$, genética aditiva direta $\left(\sigma_{a}^{2}\right)$, aditiva materna $\left(\sigma_{m}^{2}\right)$ e residual $\left(\sigma_{e}^{2}\right)$, de herdabilidades aditiva direta $\left(h_{a}^{2}\right)$, aditiva materna $\left(h_{m}^{2}\right)$ e da proporção da variância total atribuída ao erro $\left(\mathrm{e}^{2}\right)$ em touros da raça Nelore, com média de 21 meses de idade, criados extensivamente

\begin{tabular}{cccccccc}
\hline Variável & $\sigma_{p}^{2}$ & $\sigma_{a}^{2}$ & $\sigma_{m}^{2}$ & $\sigma_{e}^{2}$ & $h_{a}^{2} \pm \mathrm{EP}$ & $h_{m}^{2} \pm \mathrm{EP}$ & $\mathrm{e}^{2} \pm \mathrm{EP}$ \\
\hline PE450 & 4,66 & 1,13 & 0,47 & 3,06 & $0,24 \pm 0,05$ & $0,10 \pm 0,03$ & $0,66 \pm 0,04$ \\
PE & 5,17 & 1,91 & - & 3,26 & $0,37 \pm 0,05$ & - & $0,63 \pm 0,05$ \\
CTE & 0,99 & 0,23 & - & 0,75 & $0,24 \pm 0,05$ & - & $0,76 \pm 0,05$ \\
LTE & 0,20 & 0,06 & - & 0,14 & $0,29 \pm 0,05$ & - & $0,71 \pm 0,05$ \\
CTD & 0,98 & 0,25 & - & 0,73 & $0,26 \pm 0,05$ & - & $0,74 \pm 0,05$ \\
LTD & 0,22 & 0,68 & - & 0,15 & $0,31 \pm 0,05$ & - & $0,69 \pm 0,05$ \\
FOT & 0,21 & 0,26 & - & 0,19 & $0,12 \pm 0,04$ & - & $0,88 \pm 0,04$ \\
VOT & - & 6026,86 & - & - & $0,33 \pm 0,06$ & - & $0,67 \pm 0,06$ \\
TURB & 1,29 & 0,14 & - & 1,15 & $0,11 \pm 0,03$ & - & $0,89 \pm 0,03$ \\
MOT & 188,43 & 14,80 & - & 173,63 & $0,08 \pm 0,03$ & - & $0,92 \pm 0,03$ \\
VIG & 0,42 & 0,02 & - & 0,40 & $0,05 \pm 0,02$ & - & $0,95 \pm 0,02$ \\
DFMA & 228,96 & 45,09 & - & 183,87 & $0,20 \pm 0,04$ & - & $0,80 \pm 0,04$ \\
DFME & 40,28 & 1,02 & - & 39,26 & $0,03 \pm 0,02$ & - & $0,97 \pm 0,02$ \\
DT & 306,75 & 54,00 & - & 247,75 & $0,19 \pm 0,04$ & - & $0,81 \pm 0,04$ \\
\hline
\end{tabular}

PE450 = perímetro escrotal ajustado para 450 dias de idade; PES550 = peso corporal ajustado para 550 dias de idade; $\mathrm{PE}=$ perímetro escrotal na ocasião do exame andrológico; $\mathrm{CTE}=$ comprimento do testículo esquerdo; $\mathrm{LTE}=$ largura do testículo esquerdo; $\mathrm{CTD}=$ comprimento do testículo direito; $\mathrm{LTD}=$ largura do testículo direito; FOT $=$ formato testicular; VOT $=$ volume testicular; TURB $=$ turbilhonamento; $\mathrm{MOT}=$ motilidade; $\mathrm{VIG}=$ vigor; $\mathrm{DFMA}=$ defeitos maiores; DFME = defeitos menores; DT $=$ defeitos totais.

O baixo valor de herdabilidade observado para formato testicular (FOT), 0,12, indica que a seleção para esta característica apresentará uma resposta muito pequena. Para volume testicular (VOT), obteve-se estimativa de herdabilidade aditiva direta de 0,33. Em animais da raça Nelore, Quirino et al. (1999) registraram valor muito próximo ao deste estudo, 0,30, quando o modelo estatístico foi ajustado para peso corporal, e um valor mais alto, 0,50, quando não se considerou o peso corporal no modelo estatístico. Entretanto, houve diferenças entre as fórmulas empregadas pelos autores para cálculos do volume testicular, pois Quirino (1999) adotou a fórmula preconizada por Toelle e Robison (1985), e no presente estudo adotaram-se as fórmulas de Fields et al. (1979), para testículos com formato longo, longo-moderado e longooval, e as de Bailey et al. (1998), para testículos com formato oval-esférico e esférico. Dias (2004), utilizando a fórmula do volume da parábola, encontrou valor de 1,00 para a herdabilidade da característica VOT. Portanto, essa característica também pode ser utilizada como critério de seleção em animais da raça Nelore, quando se pretende obter animais com maior volume testicular, pois o volume testicular também influencia a produção espermática
(Bailey et al., 1996). No entanto, deve-se ressaltar a correlação elevada entre esta característica e a do PE, sendo esta última uma medida mais simples e rápida de ser obtida em campo, e de alta repetibilidade entre os técnicos, logo a mais indicada.

As estimativas de herdabilidade para características físicas do sêmen apresentam valores díspares. As condições ambientais e a estrutura dos dados podem, em parte, justificar tais diferenças. Os valores registrados foram de 0,$11 ; 0,08 ; 0,05$ para turbilhonamento (TURB), motilidade (MOT) e vigor (VIG) espermáticos, respectivamente. Assim como neste estudo, Quirino (1999), Sarreiro et al. (2000), Sarreiro (2001), Quirino et al. (2004) e Dias et al. (2006) observaram valores de herdabilidade aditiva direta para vigor espermático em animais da raça Nelore de 0,06, 0,11, 0,03, 0,12 e 0,08, respectivamente. No entanto, Bergmann et al. (1997) observaram valores de herdabilidade bem mais altos $(0,59)$, também em animais da raça Nelore. Possivelmente, os estudos mais recentes estejam estimando mais adequadamente o valor da herdabilidade para VIG. O valor registrado neste estudo para MOT está em consonância com os estimados por Bergmann et al. (1997), 
Quirino (1999) e Dias et al. (2006), que, ao estudarem dados de touros da mesma raça, observaram valores de $0,15,0,12$ e 0,10, respectivamente. Sarreiro et al. (2000) e Sarreiro (2001) registraram valor muito baixo para herdabilidade de MOT $(0,01)$ em animais da raça Nelore. No entanto, é consensual que a herdabilidade para os aspectos físicos do sêmen seja baixa e que não haja respaldo para inclusão deles em modelos de seleção.

Os defeitos espermáticos, classificados em defeitos maiores (DFMA), defeitos menores (DFME) e defeitos totais (DT), tiveram valores de herdabilidade aditiva direta de 0,20, 0,03 e 0,19 , respectivamente. Sarreiro et al. (2000) e Sarreiro (2001) estimaram valores de 0,19 e 0,07, respectivamente, para taxa de anormalidades, enquanto Dias et al. (2006) estimaram valores de herdabilidade de 0,16, 0,09 e 0,11 para DFMA, DFME e DT, respectivamente, em touros da raça Nelore. Entretanto, Quirino (1999), em touros da raça Nelore, observou altos valores de herdabilidade aditiva direta - ajustados ou não para peso corporal - para DFMA, de 0,51 e 0,59; DFME, de 0,13 e 0,21; e DT de 0,48 e 0,58. No presente estudo, as estimativas de herdabilidade das características morfológicas do sêmen foram de baixa a moderada magnitudes e indicaram a presença de variância genética aditiva, conforme relatou Quirino (1999).

$\mathrm{Na}$ Tab. 2 são apresentados os valores de herdabilidades aditiva direta, aditiva materna e as correlações genéticas das características biométricas entre si, com o PE e com PE450.

Tabela 2. Estimativas de herdabilidades aditivas direta $\left(h_{1}^{2} e h_{2}^{2}\right)$ e materna $\left(h_{M 1}^{2} e h_{M 2}^{2}\right)$ e correlações genéticas entre as características de biometria testicular de touros da raça Nelore, com média de 21 meses de idade, criados extensivamente

\begin{tabular}{|c|c|c|c|c|c|}
\hline Variável & $h_{1}^{2}$ & $h_{M 1}^{2}$ & $h_{2}^{2}$ & $h_{M 2}^{2}$ & Correlação genética \\
\hline PE450-PE & 0,33 & 0,03 & 0,37 & - & 0,77 \\
\hline PE450-FOT & 0,24 & 0,10 & 0,11 & - & 0,30 \\
\hline PE-LTD & 0,36 & - & 0,33 & - & 0,97 \\
\hline PE-LTE & 0,37 & - & 0,29 & - & 0,97 \\
\hline PE-FOT & 0,37 & - & 0,12 & - & 0,24 \\
\hline PE-VOT & 0,37 & - & 0,35 & - & 0,88 \\
\hline PE-CTD & 0,37 & - & 0,28 & - & 0,59 \\
\hline PE-CTE & 0,37 & - & 0,26 & - & 0,58 \\
\hline PE-CT & 0,37 & - & 0,72 & - & 0,12 \\
\hline CTD-FOT & 0,26 & - & 0,12 & - & $-0,52$ \\
\hline CTD-VOT & 0,27 & - & 0,33 & - & 0,85 \\
\hline CTD-LTD & 0,27 & - & 0,31 & - & 0,63 \\
\hline CTD-LTE & 0,27 & - & 0,29 & - & 0,65 \\
\hline CTD-CTE & 0,24 & - & 0,25 & - & 0,99 \\
\hline CTE-FOT & 0,24 & - & 0,12 & - & $-0,53$ \\
\hline CTE-LTD & 0,25 & - & 0,31 & - & 0,60 \\
\hline CTE-LTE & 0,25 & - & 0,29 & - & 0,65 \\
\hline CTE-VOT & 0,25 & - & 0,33 & - & 0,84 \\
\hline LTD-FOT & 0,31 & - & 0,12 & - & 0,33 \\
\hline LTD-VOT & 0,32 & - & 0,33 & - & 0,95 \\
\hline LTE-FOT & 0,29 & - & 0,12 & - & 0,28 \\
\hline LTE-LTD & 0,28 & - & 0,32 & - & 0,99 \\
\hline LTE-VOT & 0,29 & - & 0,34 & - & 0,97 \\
\hline VOT-FOT & 0,33 & - & 0,12 & - & 0,01 \\
\hline
\end{tabular}

$\mathrm{PE}$ = perímetro escrotal na ocasião do exame andrológico; PE450 = perímetro escrotal ajustado para 450 dias de idade; $\mathrm{CTE}=$ comprimento do testículo esquerdo; LTE = largura do testículo esquerdo; $\mathrm{CTD}=$ comprimento do testículo direito; LTD = largura do testículo direito; FOT = formato testicular; VOT = volume testicular. 
A correlação genética entre PE e comprimento dos testículos esquerdo e direito (CTE e CTD), 0,58 e 0,59 , foi semelhante aos valores registrados por Quirino (1999), 0,67 e 0,68, e por Bergmann et al. (1997), 0,68 e 0,67, e mais baixos que os registrados, 0,91 e 0,81 , por Dias et al. (2008). Para a largura dos testículos esquerdo e direito (LTE e LTD), o valor estimado de correlação genética com PE foi de 0,97 para as duas características, não diferindo dos valores registrados por Bergmann et al. (1997), Quirino (1999) e Dias et al. (2008), na mesma raça. $\mathrm{O} \mathrm{PE}$ apresentou correlação genética alta e positiva, 0,88, com VOT, semelhante aos valores registrados por Quirino (1999) e Dias et al. (2008), de 0,97 e 0,99, respectivamente. Correlações favoráveis e de alta magnitude entre PE com as características VOT, CTE, CTD, LTE e LTD indicam que avanços no aumento do PE refletem fortemente aumento do volume testicular, sendo a característica adequada para ser utilizada nos programas de seleção para predição do tamanho dos testículos em animais da raça Nelore.

Segundo Unanian et al. (2000), o PE é mais influenciado pela largura do que pelo comprimento dos testículos, o que poderia comprometer essa associação em animais de testículos longos. Esse fato pode ser confirmado pelas correlações genéticas negativas registradas entre o comprimento dos testículos com FOT, que apresentaram valores de $-0,52$ e $-0,53$ para CTD e CTE, respectivamente. Estes resultados sugerem que, com o aumento do comprimento testicular, a razão entre largura e comprimento tende a diminuir, correspondendo ao formato testicular alongado. O PE e $\mathrm{O}$ PE450 apresentaram correlação genética positiva e favorável com FOT, valores de 0,24 e 0,30, respectivamente. Estes indicam que a seleção para o aumento do PE traria uma resposta positivamente correlacionada para aumento do formato testicular. Porém, essa mudança não seria do formato alongado para o formato oval ou esférico, e sim dentro do formato alongado longo, longo-moderado e longo oval -, uma vez que as condições de ambiente (condições tropicais) que influenciaram o alongamento do formato testicular em zebuínos ainda estarão presentes. Embora tenham sido encontradas correlações de moderada a alta entre PE com VOT e FOT, foram registradas correlações genéticas baixas entre VOT e FOT, 0,01, demonstrando que, além de os genes que influenciam uma característica não estarem influenciando a outra, a seleção baseada no volume testicular não trará mudanças no formato testicular do rebanho.

Correlações genéticas favoráveis e de alta magnitude entre VOT e comprimento e largura dos testículos indicam a existência de base genética comum para estas características e de influência direta do comprimento e largura sobre a massa testicular. Os valores de correlações genéticas entre VOT com LTD e LTE foram de 0,95 e 0,97 , respectivamente, semelhantes aos registrados por Quirino (1999), denotando que mudanças no volume testicular podem ser alcançadas pela seleção aplicada à largura testicular. Provavelmente, os altos valores de correlações genéticas registrados nesses estudos devam-se às fórmulas utilizadas, que valorizam muito a largura testicular média. Os valores de correlações genéticas entre FOT com LTD $(0,33)$ e LTE $(0,28)$ registrados neste estudo são importantes, demonstrando que a seleção para a largura testicular pode trazer respostas correlacionadas para a mudança do formato testicular, sempre dentro da capacidade de adaptação dos zebuínos às condições tropicais, ou seja, com testículos alongados.

As altas correlações genéticas entre largura e comprimento testiculares - 0,65 para LTE x CTE e LTE x CTD, e 0,63 para LTD x CTE e 0,60 para LTD x CTD - demonstram que os genes envolvidos no crescimento testicular, em comprimento, também influenciam fortemente o crescimento testicular em largura. $\mathrm{O}$ alto valor de correlação genética entre o comprimento e entre a largura, 0,99, reflete a influência dos mesmos genes no desenvolvimento dos comprimentos testiculares direito e esquerdo e das larguras testiculares direita e esquerda, respectivamente.

$\mathrm{Na}$ Tab. 3 são sumariados os valores de herdabilidades aditiva direta, aditiva materna e as correlações genéticas entre as características físicas e morfológicas do ejaculado com o PE e o PE450.

A correlação genética entre PE e PE450 com a motilidade espermática foi de 0,39 e 0,42 , respectivamente, demonstrando existir associação genética positiva, implicando que os genes ligados à expressão do PE nas duas idades 
também influenciam a motilidade do sêmen nas avaliações andrológicas (média de 21 meses de idade). Valores mais altos, na mesma raça, foram registrados por Bergmann et al. (1997), Sarreiro (2001) e Dias et al. (2008). Entretanto, os autores comentaram que esse valor é de difícil interpretação, principalmente por ser uma característica muito influenciada por fatores residuais. Quirino (1999) observou valor de 0,13 para esta correlação genética na coleta em animais da raça Nelore de várias idades. Existem resultados diversos de correlações genéticas entre PE e motilidade, variando de 0,13 a 1,00 (Gipson et al., 1987; Bergmann et al., 1997; Quirino et al., 1999; Sarreiro et al., 2002); já os resultados de correlações genéticas entre PE e vigor variam de 0,69 a 0,99 (Bergmann et al., 1997; Quirino et al., 1999; Sarreiro et al., 2002).

Tabela 3. Estimativas de herdabilidades aditivas direta $\left(h_{1}^{2} e h_{2}^{2}\right)$ e materna $\left(h_{M 1}^{2} e h_{M 2}^{2}\right)$ do perímetro escrotal e suas correlações genéticas entre as características físicas e morfológicas do ejaculado de touros da raça Nelore, com média de 21 meses de idade, criados extensivamente

\begin{tabular}{lccccc}
\multicolumn{1}{c}{ Variável } & $h_{1}^{2}$ & $h_{M 1}^{2}$ & $h_{2}^{2}$ & $h_{M 2}^{2}$ & Correlação genética \\
\hline PE450-MOT & 0,25 & 0,09 & 0,08 & - & 0,42 \\
PE450-DFCA & 0,25 & 0,10 & 0,17 & - & $-0,13$ \\
PE450-DFCB & 0,24 & 0,11 & 0,14 & - & $-0,48$ \\
PE450-DFMA & 0,24 & 0,10 & 0,19 & - & $-0,41$ \\
PE450-DFME & 0,24 & 0,10 & 0,02 & - & $-0,02$ \\
PE450-DFPI & 0,24 & 0,10 & 0,02 & - & $-0,32$ \\
PE-MOT & 0,37 & - & 0,08 & - & 0,39 \\
PE-TURB & 0,37 & - & 0,12 & - & 0,34 \\
PE-VIG & 0,37 & - & 0,07 & - & 0,56 \\
PE-VOL & 0,37 & - & 0,05 & - & $-0,02$ \\
PE-ASP & 0,37 & - & 0,08 & - & 0,28 \\
PE-DFCA & 0,37 & - & 0,17 & - & $-0,10$ \\
PE-DFCB & 0,37 & - & 0,15 & - & $-0,08$ \\
PE-DFME & 0,37 & - & 0,02 & - & $-0,48$ \\
PE-DFPI & 0,37 & - & 0,02 & - & $-0,25$ \\
PE-DT & 0,37 & - & 0,20 & - & $-0,09$ \\
PE-DFMA & 0,37 & - & 0,20 & - & $-0,05$ \\
\hline
\end{tabular}

$\mathrm{PE}=$ perímetro escrotal na ocasião do exame andrológico; PE450 = perímetro escrotal ajustado para 450 dias de idade; $\mathrm{VOL}=$ volume do ejaculado; TURB = turbilhonamento; $\mathrm{MOT}=$ motilidade; $\mathrm{VIG}=$ vigor; $\mathrm{ASP}=$ aspecto do sêmen; DFMA = defeitos maiores; DFME = defeitos menores; DT = defeitos totais; DFCB = defeitos de cabeça; DFPI = defeitos de peça intermediária; DFCA = defeitos de cauda.

O valor de correlação genética observado entre PE e VIG foi de 0,56, corroborando com Bergmann et al. (1997) e Dias (2004), que registraram valores de 0,69 e 0,60, respectivamente. Correlações mais elevadas foram observadas por Quirino (1999) e Sarreiro (2001) em animais da mesma raça, com valores de 0,89 e 0,99 , respectivamente.

Para a correlação genética entre PE e TURB, o valor observado foi de 0,34. No entanto, Quirino (1999) observou valor de -0,29. A grande diferença entre os dois estudos decorre da diferente estruturação do banco de dados, em que os animais estudados por Quirino (1999) estavam na faixa etária de dois a cinco anos de idade e com mais de um exame andrológico no período estudado.
Quanto aos DFMA, DFME e DT, os valores de correlação genética com PE foram, respectivamente, de $-0,05,-0,48$ e $-0,09$. Com o PE450, as correlações genéticas entre DFMA e DFME foram de $-0,41$ e $-0,02$, respectivamente O sentido da relação entre os defeitos espermáticos e os PEs na coleta e aos 450 dias de idade foi negativo, logo a seleção para PE nas idades estudadas mostra-se favorável à diminuição dos defeitos espermáticos no ejaculado, em que a maior correlação favorável com DFMA foi observada com PE450.

Os valores de correlação genética entre PE e morfologia espermática neste estudo foram mais baixos que os observados por Quirino (1999). Porém, os dois estudos demonstram que há maior correlação genética entre os DFME e o PE, 
implicando que bovinos com maiores PE são mais propensos geneticamente a apresentarem menores valores de DFME. Embora o maior valor relativo para a correlação genética tenha sido verificado entre PE e DFME, essa característica apresentou a menor herdabilidade aditiva direta entre os defeitos espermáticos classificados em maiores, menores e totais -, o que caracteriza em uma situação de menor impacto indireto do melhoramento genético pela seleção do PE.

Correlações genéticas entre PE e defeitos espermáticos menores e totais, $-0,67$ e $-0,12$, apresentaram valores negativos e, respectivamente, de alta e baixa magnitudes, o que indica associação favorável entre o desenvolvimento testicular e as características morfológicas desejáveis do sêmen (Dias et al., 2008). Todavia, a correlação genética entre PE e DM, 0,13, apresentou valor oposto aos encontrados na literatura (Bergmann et al., 1997; Quirino et al., 1999).

Os resultados de correlações genéticas verificadas entre PE e características físicas motilidade e vigor - e morfológicas - DMe e DT - do sêmen são indicação da base genética comum entre elas e de que a seleção de reprodutores baseada no $\mathrm{PE}$ leva à seleção indireta favorável das características seminais, resultado semelhante ao encontrado por Dias et al. (2008) e Sarreiro et al. (2002).

\section{CONCLUSÕES}

As características biométricas testiculares apresentam valores de herdabilidade moderados a altos, enquanto as características seminais valores baixos. As correlações genéticas entre perímetro escrotal com todas as características reprodutivas (biométricas, físicas e morfológicas do ejaculado) foram favoráveis, sendo indicado como característica de escolha na avaliação e seleção de touros da raça Nelore, com média de 21 meses de idade. $O$ volume testicular apresentou alta correlação genética com o perímetro escrotal, o que não justifica a utilização do volume testicular para a seleção de touros da raça Nelore. Os defeitos espermáticos, avaliados ao exame andrológico, apresentam caráter genético, porém de baixa magnitude.

\section{AGRADECIMENTOS}

À Agropecuária CFM Ltda por disponibilizar a propriedade e animais utilizados na análise de dados.

\section{REFERÊNCIAS}

BAILEY, T.L.; HUDSON, R.S.; POWE, T.A. et al. Caliper and ultrasonographic measurements of bovine testicles and a mathematical formula for determining testicular volume and weight in vivo. Theriogenology, v.49, p.581-594, 1998.

BAILEY, T.L.; MONKE, D.; HUDSON, R. S. et al. Testicular shape and its relationship to sperm production in mature Holstein bulls. Theriogenology, v.46, p.881-887, 1996.

BERGMANN, J.A.G.; QUIRINO, C.R.; VALE FILHO, V.R. et al. Herdabilidades e correlações genéticas entre medições testiculares e características espermáticas em touros Nelore. Arch. Latinoam. Prod. Anim. v.5, p.473-475, 1997.

BLOM, E. Pathological conditions in the genital organs and in semen as ground for rejection of breeding bulls for import or export to and from Denmark, 1958 - 1982. Nord. Vet. Med., v.35, p.105130, 1983.

BOLDMAN, K.G.; VAN VLECK, L.D. User's guide MTDFREML. Department of Agriculture, U.S. 1993.

CORAH, L.R.; RITCHIE, H.; SELK, G. The reproductive and nutritional management of beef bulls. In: Beef Cattle Handbook - Product of Extension Beef Cattle Resource Committee, n.2030, p.1-5, 1994.

DIAS, J.C.; ANDRADE, V.J.; MARTINS, J.A.M. et al. Correlações genéticas e fenotípicas entre características reprodutivas e produtivas de touros da raça Nelore. Pesq. Agrop. Bras., v.43, p.53-59, 2008.

DIAS, J.C.; ANDRADE, V.J.; FRIDRICH, A.B. et al. Estimativas de parâmetros genéticos de características reprodutivas de touros Nelores, de dois e três anos de idade. Arq. Bras. Med. Vet. Zootec., v.58, p.388-393, 2006.

DIAS, J.C. Aspectos andrológicos, biometria testicular e parâmetros genéticos de características reprodutivas de touros nelore, de dois e três anos de idade, criados extensivamente no Mato Grosso do Sul. 2004. 54f. Dissertação (Mestrado em Medicina Veterinária) - Escola de Veterinária, Universidade Federal de Minas Gerais, Belo Horizonte. 
DIAS, L.T.; EL FARO, L.; FRIES, L.A. et al. Estimativas de parâmetros genéticos para perímetro escrotal e idade ao primeiro parto em animais da raça Nelore. In: Reunião da Sociedade Brasileira de Zootecnia, 37., 2000, Viçosa. Anais... Viçosa - Minas Gerais, 2000.

ELER, J.P.; FERRAZ, J.B.S.; SILVA, P.R. Parâmetros genéticos para peso, avaliação visual e circunferência escrotal na raça Nelore, estimados por modelo animal. Arq. Bras. Med. Vet. Zootec., v.48, p.203-213, 1996.

FIELDS, M.J.; BURNS, W.C.; WARNICK, A.C. Age, season and breed effect on testicular volume and semen traits in young beef bulls. J. Anim. Sci., v.48, p.1299-1304, 1979.

GARNERO, A.V.; LÔBO, R.B.; BEZERRA, L.A.F. et al. Comparação entre alguns critérios de seleção para crescimento na raça Nelore. Rev. Bras. Zootec., v.30, p.714-718, 2001.

GIPSON, T.A.; VOGT, D.W.; ELLERSIECK, M.R. et al. Genetic and phenotypic parameter estimates for scrotal circumference and semen traits in young beef bulls. Theriogenology, v.28, p.547-555, 1987.

HANCOCK, J.L. The morphology of boar spermatozoa. J. Roy. Microsc. Soc. v.76, p.84-97, 1957.

HENDERSON, C.R.; QUAAS, R.L. Multiple trait evaluation using relative's records. J. Anim. Sci., v.46, p.1188, 1976.

MARCONDES, C.R.; GAVIO, D.; BITTENCOURT, T.C.C. et al. Estudo de modelo alternativo para a estimação de componentes de (co)variância e predição de valores genéticos de características de crescimento em bovinos da raça Nelore. Arq. Bras. Med. Vet. Zootec., v.54, 93-99, 2002.

ORTIZ PEÑA, C.D.; QUEIROZ, S.A.; FRIES, L.A. Comparação entre critérios de seleção de precocidade sexual e a associação destes com características de crescimento em bovinos Nelore. Rev. Bras. Zootec., v.30, p.93-100, 2001.

PEREIRA, E.; ELER, J.P.; FERRAZ, J.B.S Correlações genéticas entre perímetro escrotal e algumas características reprodutivas na raça Nelore. Rev. Bras. Zootec, v.29, p.1676-1683, 2000.
QUIRINO, C.R. Herdabilidades e correlações genéticas entre medições testiculares, características seminais e libido em touros Nelore. 1999. 104f. Tese (Doutorado) - Escola de Veterinária, Universidade Federal de Minas Gerais, Belo Horizonte.

QUIRINO, C.R.; BERGMANN, J.A.G.; VALE FILHO, V.R. et al. Evaluation of four mathematical functions to describe scrotal circumference maturation in Nellore cattle. Theriogenology, v.52, p.25-34, 1999.

SARREIRO, L.C. Estimativas de herdabilidades e correlações genéticas entre o perímetro escrotal, características seminais e libido de touros da raça Nelore. 2001. 36f. Dissertação (Mestrado) - Escola de Veterinária, Universidade Federal de Minas Gerais, Belo Horizonte.

SARREIRO, L.C.; BERGMANN, J.A.G.; QUIRINO, C.R. et al. Herdabilidade e correlação genética entre perímetro escrotal, libido e características seminais de touros Nelore. Arq. Bras. Med. Vet. Zootec., v.56, p.602-608, 2002.

SARREIRO, L.C.; QUIRINO, C.R.; PINEDA, N.R. et al. Associações genéticas entre libido, perímetro escrotal e qualidade dLo sêmen de tourinhos da raça Nelore. In: Simpósio Nacional de Melhoramento Animal, 3., 2000, Belo Horizonte. Anais... Belo Horizonte: SBMA, 2000, p.449-451.

STATISTICAL Analysis System - SAS USER'S GUIDE: Statistics. 8.ed. Cary: Sas Institute Inc., 956p., 1999.

SOUZA, J.C.; SILVA, L.O.C.; FILHO, K.E. et al. Estudio de las correlaciones genéticas y de ambiente para el peso al destete en bovinos de la raza Nelore en el Brazil. Arch. Latinoam. Prod. Anim. v.5, p.485-487, 1997.

TOELLE, V.D.; ROBISON, O.W. Estimates of genetic correlations between testicular measurements and female reproductive traits in cattle. J. Anim. Sci., v.60, p.89-100, 1985

UNANIAN, M.M.; SILVA, A.E.D.F.; McMANUS, C. et al. Características biométricas testiculares para avaliação dos touros zebuínos da raça Nelore. Rev. Bras. Zootec., v. 29, p.136-144, 2000.

VASCONCELOS SILVA, J.A.II; DIAS, L.T; ALBUQUERQUE, L.G. Estudo genético da precocidade sexual de novilhas em um rebanho Nelore. Rev. Bras. Zootec., v.34, p.1568-1572, 2005. 